University for Business and Technology in Kosovo

UBT Knowledge Center

UBT International Conference

2017 UBT International Conference

Oct 28th, 2:00 PM - 3:30 PM

\title{
“Nephron Sparing Surgery” in a Tumor Greater than 7 Cm
}

\author{
Isa Haxhiu \\ University Clinical Center of Kosova, isa_haxhiu2@hotmail.com \\ Xhedet Çuni \\ University Clinical Center of Kosova \\ Xhedet Çuni \\ University Clinical Center of Kosova \\ Rexhep Kasumaj \\ University Clinical Center of Kosova \\ Anduenë Haxhiu \\ University Clinical Center of Kosova
}

See next page for additional authors

Follow this and additional works at: https://knowledgecenter.ubt-uni.net/conference

Part of the Medicine and Health Sciences Commons

\section{Recommended Citation}

Haxhiu, Isa; Çuni, Xhedet; Çuni, Xhedet; Kasumaj, Rexhep; Haxhiu, Anduenë; Sejdiu, Armir; Haxhiu, Emirjon; and Haxhiu, Rinor, "'Nephron Sparing Surgery" in a Tumor Greater than 7 Cm" (2017). UBT International Conference. 287.

https://knowledgecenter.ubt-uni.net/conference/2017/all-events/287

This Event is brought to you for free and open access by the Publication and Journals at UBT Knowledge Center. It has been accepted for inclusion in UBT International Conference by an authorized administrator of UBT Knowledge Center. For more information, please contact knowledge.center@ubt-uni.net. 


\section{Presenter Information}

Isa Haxhiu, Xhedet Çuni, Xhedet Çuni, Rexhep Kasumaj, Anduenë Haxhiu, Armir Sejdiu, Emirjon Haxhiu, and Rinor Haxhiu 


\title{
"Nephron Sparing Surgery" in a Tumor Greater than 7 $\mathrm{Cm}$
}

\author{
Isa Haxhiu ${ }^{1,4}$, Xhedet Çuni ${ }^{1}$,Emirjon Haxhiu ${ }^{1}$, Rexhep Kasumaj ${ }^{1}$, Rinor Haxhiu \\ ${ }^{1}$, Salih Krasniqi ${ }^{2,4}$, Besnik Elshani ${ }^{3,4}$, Anduenë Haxhiu ${ }^{1}$ \\ ${ }^{1}$ Unuiversity Clinical Centre of Kosovo, Urologic Clinic \\ ${ }^{2}$ University Clinical Centre of Kosovo, Abdiminal Surgery Clinic \\ ${ }^{3}$ University Clinical Cetnre of Kosovo, Neurosurgery Clinic \\ ${ }^{4}$ Faculty of Nursing, UBT - Higher Education Institution, Lagjja Kalabria, 10000 p.n., \\ Prishtine, Kosovo \\ isa.haxhiu@ubt-uni.net
}

\begin{abstract}
We present a case of nephron sparing surgery (NSS), of a patient,68 years olld, resident in e Prizren, who had a tumor bigger than $7(8.5 \mathrm{~cm})$, meaning T2a staging tumor.Renal cell carcinoma (RCC) is a common malignancy with an increasing incidence1. NSS was proven feasible decades ago for patients with imperative indications to preserve maximum kidney function, for instance solitary kidney, bilateral renal tumors, or moderate/severe chronic kidney disease (ChKD)2. The goal of partial nephrectomy is complete excision of potentially malignant tissue without malignant cells at the border of the surgical specimen, with maximum preservation of nearby normal renal parenchyma.It is known that nephron sparing surgery is preferred for T1a and $\mathrm{T} 1 \mathrm{~b}$, or when the tumor is limited in kidneys and not greater than $7 \mathrm{~cm}$.In this case, the tumor has passed T1 staging, it belonged to T2 staging. We succeeded doing the "nephron sparing surgery", saving less than half of the kidney. The approach to a SRM( small renal masses) is based on tumor size, stage, and location.Most NSS requires renal vessel occlusion during the excision, and renal tubular tissue is particularly sensitive to ischemia; the WIT ( warm ischemia time ), therefore, should be minimized. Damage to renal tubular tissue is directly related to WIT. Although the upper limit of WIT is debatable, a limit of 20 minutes is a generally accepted guideline.The kidney can be approached with traditional "open" surgery or laparoscopically. For SRMs appropriate for NSS, open partial nephrectomy represents the gold standard. This approach has the most data regarding oncologic and renal function outcomes, with long-term cancerspecific survival rates exceeding $90 \% 3$. We can conclude that "nephron sparing surgery" in specific cases can be used also for patients with T2a staging tumor, for those patients were there is hope that they can benefit from this procedure. The patient has stayed in our clinic for ten days, and is released in a good health condition, unfortunately the remaining renal parenchyma was not sufficient to perform its function, because of the chronic pyelonephritis with an emphasized hypoplasia of the other kidney ( left kidney). So the only benefit of this procedure in this patient was that instead of doing the dialysis three times a week, he could do it two times a week.
\end{abstract}

Keywords: Nephron sparing surgery, renal carcinoma, partial nephrectomy, papillary renal cell carcinoma.

\section{Introduction}

The incidence of kidney cancer continues to increase with the growth of the world population age (4). Today, RCC accounts for $3 \%$ of adult tumors, and the highest incidence ranges between 
50 and 70 years. In the European Union, almost every year, 20,000 new patients with kidney kidney disease are discovered. It is thought that the use of ultrasound and CT is responsible for an increased discovery of asymptomatic tumors in the early stages, which causes these tumors not to undergo radical nephrectomies. Today most of the new tumors discovered are less than 4 $\mathrm{cm}$ in the time of their detection (5). Small kidney tumors have a low metastatic potential, so they can take care of being actively or thermally ablated. Sometimes, resuscitation of the solid kidney stones of their treatment, when they can be suspected to be malignant.

For many decades, radical nephrectomy was a gold standard for the treatment of localized renal carcinomas, although radical nephrectomy is a risk factor for the development of chronic kidney disease, leading to many cardiovascular diseases and lower survival (6-7).

Despite the fact that random comparative analysis of patients with partial and radical nephrectomy in patients with normal contralateral kidneys for tumors up to $5 \mathrm{~cm}$ in diameter did not show a survival advantage for partial nephrectomy (8) according to the guidelines of the European Urology Association (EAU), however, support the use of a more conservative surgical intervention for kidneys, whenever possible, for cT1a and b (9) tumors. Already many analyzes show a greater efficiency and greater safety of kidney replacement interventions (10). Even now, this type of kidney replacement intervention is in the trend and I have begun to use it extensively, even for T2a tumors, as is the case that we will present below.

The first surgery of a renal tumor was performed by Czerny in 1887 (11). Obviously, the nephron sparing surgery (NSS) in the past was only performed in indispensable situations, chronic kidney failure, chronic pyelonephritis with azotemia syndrome, or renal tumors, then when a radical nephrectomy would lead the patient to dialysis. With time and after an ever-increasing rescue surgery experience, the number of conservative conservation interventions with choices made and reports published on patients with small peripheral unsafe malignant lesions (12) increased. If all the suspected tumors are treated with radical nephrectomy, a significant number of nonmalignant kidneys, they can be recovered, such as angiomyolypomas, onocytomas, cystic nephromas and complicated cysts (13). Since 2002 we have provided partial nephrectomy for a selected group of patients with various localized malignant and benign tumors, even as we present, ie a cT2a, a tumor with dimensions over $7 \mathrm{~cm}$,

\section{Materials and methods}

Our work is of a retrospective-perspective type, so this work has been taken in treatment, patients undergo partial ufrectomy at the Urology Clinic, from the beginning of 2002 to November 207. The analysis takes into account the epidemiological data age and sex, the preoperative images were compared, compared to postoperative (Ct. Urography), histopathology and tumor size, histopathological type and tumor graft according to Fuhrman et al.

Of the total of 137 patients being considered, $43(31.38 \%)$ were subject to partial partial (partial) hypertension; patients were not randomized and the indication for partial nephrectomy was the result of case discussions at the Clinical College, with an individual's appointment of the surgeon himself, in agreement with the patient and family, after an exhaustive discussion with them. Twenty-eight males $(65.11 \%)$ and the 15 th female $(34.89 \%)$ was included in our treatment, with an average age of 48 years, ranging from 22 to 73 years. The blood analyses of these patients resulted from the normal ones to those of an easy anemia, while urea and creatinine, to a heavy azotemia, as is the case of the patient we will be presenting. Most tumors were discovered by chance during ultrasound examination or $\mathrm{Ct}$. for completely other problems, from symptoms that had little to do with kidney disease. From all cases identified with localized kidney cancer, most of them were first identified with ultrasound, 32; 7 with ct. and 4 with MRI. The average tumor diameter of $3.9 \mathrm{~cm}$, while ours we are describing, exceeded $8 \mathrm{~cm}$ in height. Of all localized tumors, most of them were found in the upper pole, 21 of them, 19, in the lower and third poles, were found middle of kidney. 


\section{Results and Discussion}

In all cases, the intervention was performed with a lumbotomy, often with the 12th rib, with the opening to the half of the abdomen of the respective side, going through the layers to the corresponding the flank 1 loge. After the opening of the Gerota s fascia, we release the kidney from the entire perirenal tissue, exposing the entire kidney, and then approaching the tumor by exposing the renal pedicles and by performing the clamping of the same ("hot ischemia") to work on a bloodless ground, given that tumor removal, limited to $2 \mathrm{~mm}$ from tumor bones, will not last more than 20 minutes. It's been a great deal in the case that we are showing you a right kidney tumor with size over $8 \mathrm{~cm}$, or $8.5 \mathrm{~cm}$. (T2b-fig. 1), in a patient who is in dialysis, due to chronic pyelonephritis and contralateral kidney hypoplasia. During the intervention after the tumor has been completely removed (Fig.2), we make suture of the calyxes (sealing the calyxes) and closing the kidneys with the sutures of the mattress and the sebaceous tissue as suture supporters (Fig. 3). After closing the operator wound according to the layers, we put a drain into the flank lodge. The patient wakes up in the operating room and the intervention goes smoothly.

The patient is released at home after ten days, and before we release to the home, we make an ultrasound examination (Fig. 4) and we see a kidney with a good, but insufficient to relieve the patient from the dialysis. However, the patient has another benefit, in spite of the chances of a longer survival, going twice a week instead of three times a week, before the intervention.

The pathological examination outcome, resulted in papillary carcinoma of clear kidney cells, pT2a.

The patient, even nine months after the operation, has a general stable condition without signs of recurrence and goes to dialysis twice a week. 

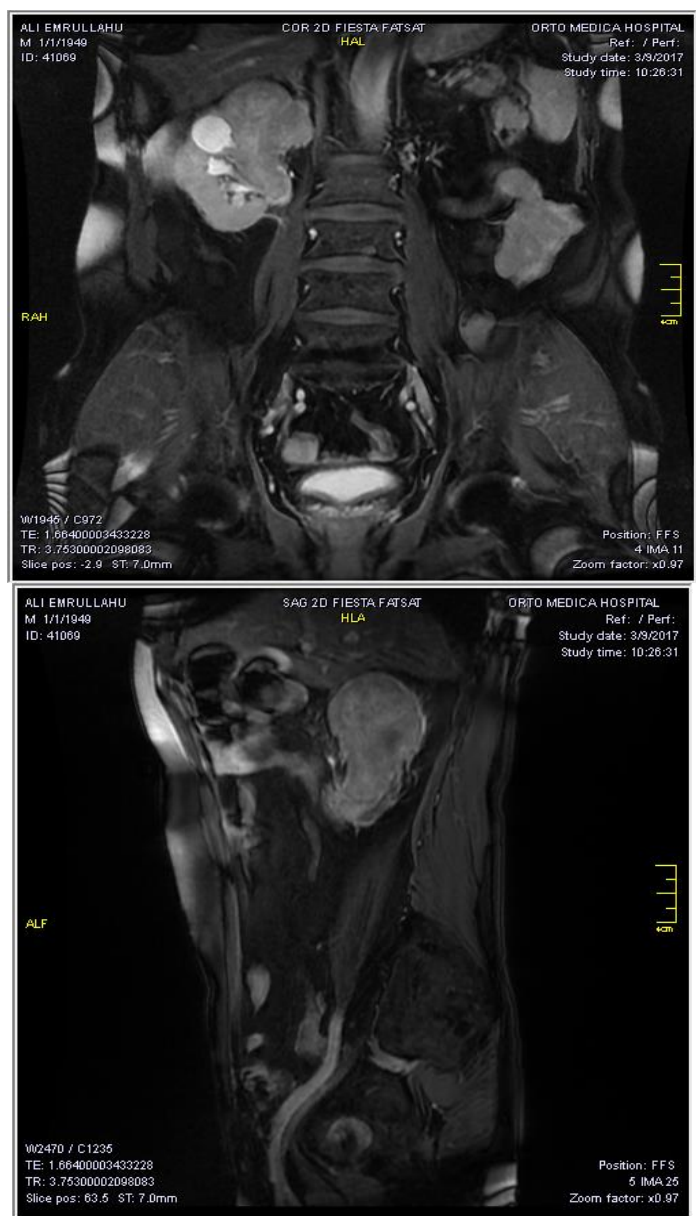

Figure 1. A right kidney tumor.

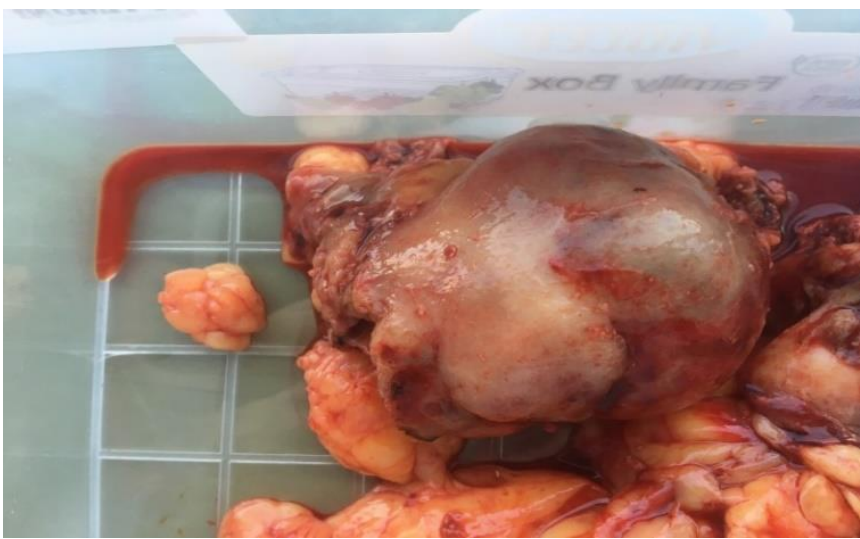

Figure 2. Completely removed tumor. 

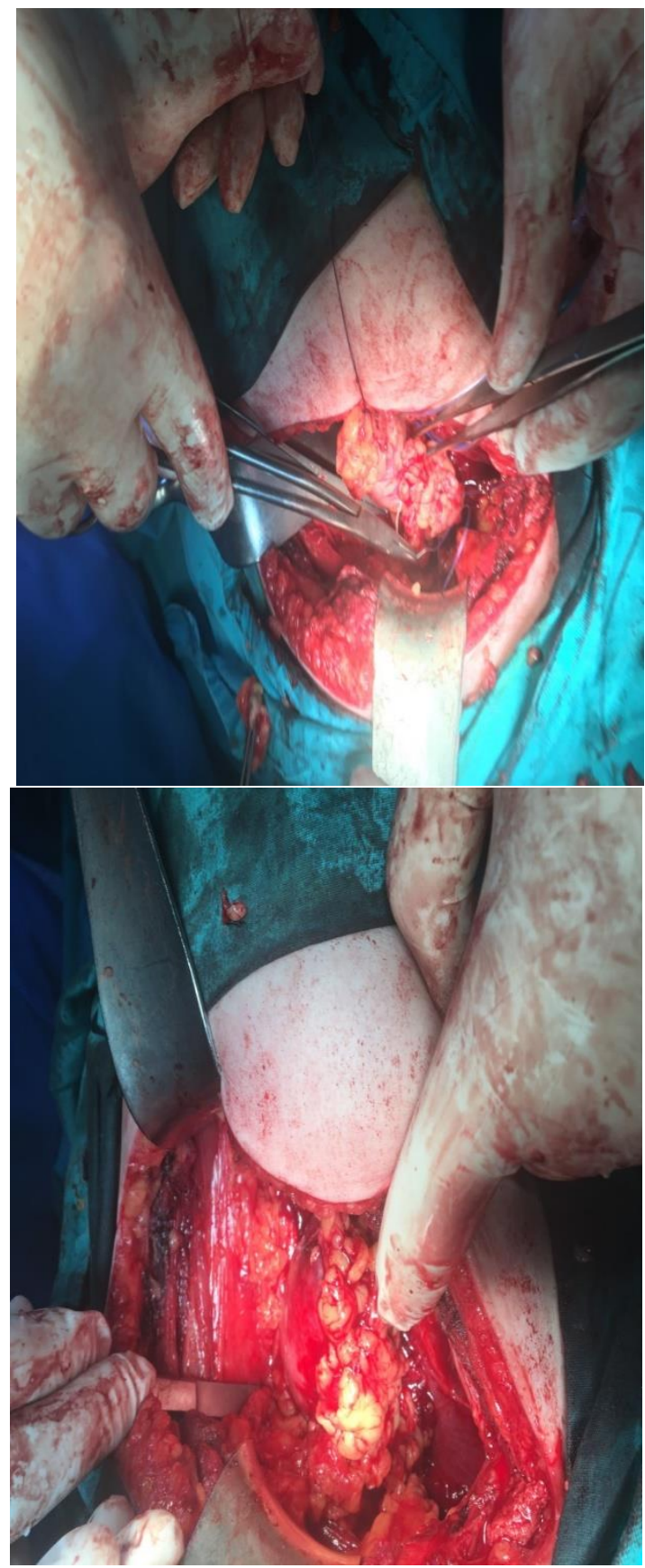

Figure 3. Suture of the calyxes (sealing the calyxes) and closing the kidneys. 


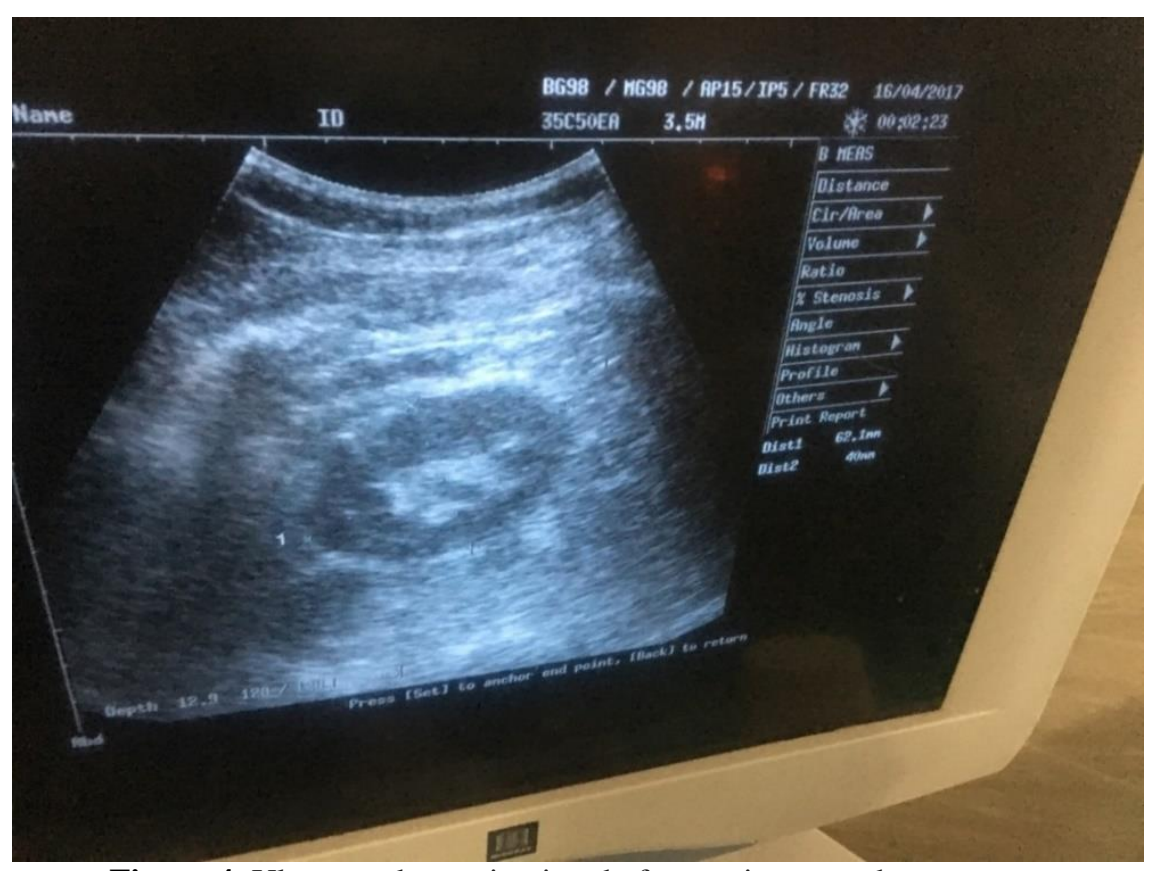

Figure 4. Ultrasound examination, before patient goes home.

Partial nephrectomy, as a standardized method for solid localized tumors, all over the developed world, has a good standardization in us, thanks to the urology experience and the loyal pursuits of the EAU guidelines, which for most of our urologists now are mandatory. Partial nephrectomy (NSS), in terms of treatment and prognosis, is now almost the same as that of radical nephrectomy. We are living in the mini-invasive surgery time, laparoscopy, and mini-invasive interventions assisted by the robot (14), radical nephrectomies are almost standard to all urologists living in developed countries, but not of countries that have an economic stagnation, and of course technological, which has already become addicted to medicine and can be talked to a contemporary and advanced physician. However, partial salvaging nephrectomy has not yet become the standard of mini-invasive surgery, because it also depends on the indigenous individual skills, from surgeon-urologist. However, in the hands of a skilled surgeon, it is already a golden standard with all the advantages that offers minimal invasive surgery and the patient as a subject. Nephron sparing surgery (NSS) in renal cell cancers, remains the elective treatment for those patients, who would have to undergo a surgical procedure, however the duration of partial nephrectomy is compared with the ablation of cT1 renal masses, and it is shown that both procedures have a similar pace in the local repetition. Of course, this retrospective analysis should be interpreted carefully because of a possible selection bias (15). Active surveillance has also been studied in patients with small kidney masses and this approach is not associated with a higher degree of metastatic progress, compared to ablative treatments (16). These authors demonstrated that maintaining of the renal function was equal in active surveillance, even in partial nephrectomy patients, meaning that partial nephrectomy is able to preserve the kidney function, in absolute majority of patients. Partial nephrectomy of renal tumors as a new standard for the treatment for renal tumors, is mainly due to tumors of T1a and T1b tumors, but rarely applicable for T2a tumors, as I have established and performed. Such intervention is possible only under the conditions of a warm ischemia (clamping the vascular pedicle(17), when the tumor removal does not last more than 20 minutes, otherwise, in all cases when warm ischemia (clamping the vascular pedicle) lasts more than 20 minutes, cold ischemia should be applied, 
which lasts the time of tumor removal up to 40 minutes. When we clamping the vascular pedicle , the use of Manitol before clamping, has been a controversial issue for quite some time, but it has been proven that there is no benefit when the pre-clamp set by its use, and its used, no extend the life of the kidney (18),

What should be considered during the partial purulent nephrectomy procedure consists in cleansing the surrounding tumor area, or when it comes to tumor multifocal tumors, a cleaner area around the tumor should be provided by resounding in a no more less than $2 \mathrm{~mm}$, from the edges of the tumor. Usually we do the cut of the tumor with the electrocution only of the surface layer part of the resonance with the rest of the nucleus with the index finger, and if the tumor also includes the pelvis and calyces system, then this part is harvested with electric scalpel or more scissors and then we make suture of calyces with Vicril threads, 3.0. So, removal of the tumor as well as the chance of showing off is combined, enucleated -resection procedures, but resulting in a satisfactory result. Such an approach is already advocated by many other urologists (19) and it seems that this is the best way for such intervention.

Since it has been shown that the decline in renal function after partial nephrectomy, is related to the loss of nephrons (20), I must be careful to be more sparing, so that as little as we can get healthy tissue, just as I have acted in all cases and even in the case that I have been exposed. It has been mentioned that in none of the cases I have executed complete kidney nephrectomy, as a consequence of intra and postoperative bleeding, although the literature also describes such cases (20). Our results are supported in the careful sewing of the pelvis and calyces system. We apply kidney drainage, with stent $6 \mathrm{Ch}$, to provide urine flow and to prevent ureteral closure, from blood coagulant, which may compromise the entire intake. Placing a drain to drain the kidney, we consider it a mandatory part of the intervention.

\section{Conclusion}

We may conclude that "spontaneous neuronal surgery" (CNR-NSS) in special cases can also be used for people with tumor pT2a, for persons who are expected to benefit from this procedure, such as in our case. The patient stays at our clinic for ten days and is released at home in good health. However, the only benefit of this patient out of this surgical procedure was to go twice in dialysis, instead of three times as it was before and perhaps a greater survival.

\section{References:}

1. Lipworth L Tarone R E McLaughlin J K The epidemiology of renal cell carcinoma J Urol 2006176(6 Pt 1):2353-2358. [PubMed];

2. Lane B R Novick A C Nephron-sparing surgery BJU Int 200799(5 Pt B, 5b):12451250.[PubMed]

3. Fergany A F, Hafez K S, Novick A C. Long-term results of nephron sparing surgery for localized renal cell carcinoma: 10-year followup. J Urol. 2000;163(2):442-445. [PubMed]

4. Znaor A, Lortet-Tieulent J, Laversanne M, Jemal A, Bray F. International variations and trends in renal cell carcinoma incidents and mortality; European Urology 2015, 67, 519530

5. Kane CJ, Mallin K, Ritchey J, Cooperberg MR, Carroll PR. Renal cell cancer stage migration: analysis of the national cancer database; Cancer 2008, 113, 78-83

6. Weight CJ, Larson BT, Fergany AF et al. Nephrectomy induced chronic renal insufficiency associated with increased risk of cardiovascular death and deaths from any cause in patients with localized cT1b renal masses. Journal of Urology, 183, 1317-1323, 2010 
7. Thompson RH, Boorjian SA, Lohse CM et al. Radical nephrectomy for pT1a renal masses may be associated with the increased overall survival compared with partial nephrectomy. Journal of Urology 179, 468-471, 2008

8. Van Poppel H, Da Pozzo L, Albrecht W et al. A prospective, randomised EORTC intergroup phase 3 study comparing the oncologic outcome of elective nephron-sparing surgery and radical nephrectomy for low-stage renal cell carcinoma. European Urology, 59, 543-552, 2011

9. Ljunberg B, Bensalah K, Canfield S, et al. Guidelines on renal cell carcinoma updated 2014. European Urology 67 (5), 913-924, 2015

10. Van Poppel H. Efficacy and safety of nephron-sparing surgery. International Journal of Urology 17 (4), 314-326, 2010

11. Van Poppel H, Claes H, Willemen P, Oyen R, Baert L. Is there a place for conservative surgery in the treatment of renal carcinoma? British Journal of Urology, 67 (2), 129-133, 1991

12. Vermooten V. Indications for conservative surgery in certain renal tumors: a study based on growth pattern of the cell carcinoma. Journal of Uology, 64, 200-206, 1950

13. Bazeed MA, Schärfe T, Becht E, Jurincic C, Alken P, Thüroff JA. Conservative surgery of renal cell carcinoma. European Urology 12 (4), 238-243, 1986

14. Van Poppel H. NSS in renal carcinoma. Brazilian Journal of Urology 26 (4), 342-353, 2000

15. Danzig MR, Ghandour RA, Chang P, Wagner AA, Pierorazio PM, Allaf ME, McKiernan JM. Active surveillance is superior to radical nephrectomy and equivalent to partial nephrectomy for preserving renal function in patients with small renal masses: results from the DISSRM registry. Journal of Urology, 194, 903-909, 2015

16. Carini M, Minervini A, Masieri L, Lapini A, Serni S. Simple enucleation for the treatment of PT1a renal cell carcinoma: our 20-year experience. European urology, 50 (6), 1267 1271, 2006

17. Blum KA, Paulucci DJ, Abaza R, Eun DD, Bhandari A, Delto JC, Krane LS, Hemal AK, Badani KK. Main renal artery clamping with or without renal vein clamping during robotic partial nephrectomy for clinical T1 renal masses: perioperative and long-term functional outcomes. Urology, 97, 118-123, 2016

18. Power NE, Maschino AC, Savage C, Silberstein JL, Thorner D, Tarin T, Wong A, Touijer KA, Russo P, Coleman JA. Intraoperative mannitol use does not improve long-term renal function outcomes after minimally invasive partial nephrectomy. Urology, 79 (4), 821 825,2012

19. Carini M, Minervini A, Masieri L, Lapini A, Serni S. Simple enucleation for the treatment of PT1a renal cell carcinoma: our 20-year experience. European urology, 50 (6), $1267-$ 1271, 2006

20. Minervini A, Campi R, Sessa F, Derweesh I, Kaouk JH, Mari A, Rha KH, Sessa M, Volpe A, Carini M, Uzzo RG. Positive surgical margins and local recurrence after simple enucleation and standard partial nephrectomy for malignant renal tumors: systematic review of the literature and metaanalysis of prevalence. Minerva Urology Nefrology, 2017 Jan 26, doi: 10.23736/S0393-2249.17.02864-8 